\title{
Data driven attempt to create a clinical algorithm for identification of women with rheumatoid arthritis at high risk of osteoporosis
}

Tore K Kvien, Glenn Haugeberg, Till Uhlig, Jan A Falch, Johan I Halse, Willem F Lems, Ben A C Dijkmans, Anthony D Woolf

\begin{abstract}
Objectives-To examine relations between osteoporosis and low bone mass and demographic and clinical variables in patients with rheumatoid arthritis (RA), in an attempt to develop a data driven clinical tool for identification of patients at high risk of osteoporosis.
\end{abstract}

Methods-All patients were recruited from a county based register and were examined cross sectionally with a variety of clinical and health status measures as well as bone density measures (anteroposterior spine L2-4, total hip, and femoral neck). Associations between osteoporosis ( $T$ score $\leqslant-2.5 \mathrm{SD}$ ) and low bone mass ( $T$ score $\leqslant-1 \mathrm{SD}$ ), on the one hand, and demographic and clinical measures, on the other, were examined bivariately and by logistic regression analyses.

Results-394 patients with a mean age of 54.8 years were examined. The percentages having osteoporosis/low bone mass were $16.8 / 45.8,14.7 / 54.5$ and $14.7 / 55.5$ in spine L2-4, total hip, and femoral neck, respectively. Osteoporosis and low bone mass were bivariately related to age, body mass index (BMI), disease duration, disease process measures, presence of deformed joints, physical disability, current use of corticosteroids, and history of nonvertebral fracture. In multivariate analyses, age $>60$ years, low BMI, and current use of corticosteroids were consistently related to osteoporosis and to low bone mass at all sites. The presence of deformed joints was associated with osteoporosis at the total hip, and a history of previous non-vertebral fracture with osteoporosis at the femoral neck. The Modified Health Assessment Questionnaire (MHAQ) $\geqslant 1.5$ and non-vertebral fracture were also independently associated with low bone mass at the hip. The logistic regression analyses models could, however, only predict osteoporosis with a sensitivity of about $50-60 \%$ and a specificity of $80-90 \%$ at the various measurement sites, and low bone mass with a sensitivity and specificity of about $70 \%$.

Conclusion-Consideration of demographic and disease markers may be of some help in predicting presence of osteoporosis or low bone mass, but a combination of markers cannot be used as a clinical tool with sufficient sensitivity and specificity for the identification of osteoporosis or low bone mass in patients with RA.

(Ann Rheum Dis 2000;59:805-811)

Osteoporosis is recognised as a complication of rheumatoid arthritis (RA) (see review ${ }^{1}$ ). Several studies have explored the relation between osteoporosis, on the one hand, and demographic and disease related variables, on the other. ${ }^{23}$ Use of corticosteroids has been found to be related to osteoporosis in RA, ${ }^{4}$ and several studies have also indicated that the development of bone loss (osteoporosis) is related to disease activity, especially early in the disease course. $^{56}$

Guidelines have been issued on the management of osteoporosis with corticosteroids. ${ }^{78}$ These guidelines have also included directions on which patients to select for diagnostic osteoporosis procedures, including bone mineral densitometry (BMD). Such guidelines have partly been based on published scientific data, partly on expert opinions, and partly on consenting group processes.

Longitudinal data are generally required to make statements about causal relations. However, for the clinician facing individual patients retrospective evaluation of a series of markers of disease activity and severity is usually not available. Thus the clinician must often rely on cross sectional data to identify patients at high risk of osteoporosis being candidates for diagnostic procedures. Recently, the need for a clinical algorithm for osteoporosis in patients with RA has been discussed. ${ }^{9}$ A preliminary proposal was made to measure bone density in patients with RA fulfilling two out of three of the following criteria: (a) age above 60, (b) immobility, and (c) high disease activity, defined as mean $C$ reactive protein (CRP) above $20 \mathrm{mg} / 1$ or persistently raised erythrocyte sedimentation rate (ESR) above $20 \mathrm{~mm} / 1 \mathrm{st} \mathrm{h}^{9}{ }^{9}$

Previous studies on the identification of clinical and demographic variables predicting high risk of osteoporosis have been performed in rather limited patient numbers recruited from clinical settings, with a possible overrepresentation of patients with RA using corticosteroids and with active and severe disease. Our present approach was to examine a large number of patients recruited from a county based RA register in an attempt to develop a clinical tool to identify female patients who require diagnostic procedures and treatment.
Accepted for publication 15 March 2000 


\section{Materials and methods}

SETTING AND INCLUSION CRITERIA

A register of patients with RA has been established in the county of Oslo since $1994 .{ }^{10}$ Inclusion criteria are a diagnosis of $\mathrm{RA}^{11}$ and a residential address in Oslo. The register is continuously updated with new cases and also withdrawals due to death or new addresses outside Oslo.

The register has been shown to be about $85 \%$ complete in the age range 18-79 years, and it has been successful in providing data on incidence, ${ }^{12}$ prevalence, and disease severity of RA. ${ }^{10}$

Inclusion criteria for the present study were enrolment in the Oslo RA register, female sex, and age between 18 and 70 years (born 1926 or later). The number of patients with RA fulfilling the inclusion criteria was 721 . Of these 721 patients, 394 white subjects were willing to meet for clinical examination and BMD measurement (attendance rate 55\%). ${ }^{13}$ All patients were younger than 70 years when completing the data collection (clinical data and BMD).

COLLECTION OF CLINICAL DATA

The collection of data was performed during a 15 month period between September 1996 and December 1997. Clinical data were collected partly by questionnaire, partly by interview and examination by trained research nurses under the supervision of a rheumatologist.

The following demographic variables were assessed: age, disease duration, body weight (light indoor clothing), and height. From the two last measures the body mass index (BMI) was computed. Comorbidities, exposure to oestradiol (current or not current user), menopause status, and previous oophorectomy were recorded as well as a history of previous non-vertebral fracture. Lifestyle variables included smoking (current, previous, never).

Disease activity was assessed by the following eight variables: 28 tender and 28 swollen joint counts, patients' and investigators' global assessment of disease activity (on a five point categorical scale and $100 \mathrm{~mm}$ visual analogue scale (VAS), respectively), pain severity and fatigue on $100 \mathrm{~mm}$ VAS, and acute phase reactants by ESR and CRP. The disease activity score (DAS) was computed using 28 joint counts. ${ }^{14}$

Damage was assessed by the number of deformed joints (score 0-18), and functional health status by the Modified Health Assessment Questionnaire (MHAQ) (range 1-4). ${ }^{15}$

Use of corticosteroids was assessed as a categorical variable (never user, previous user, current user).

BMD MEASUREMENTS

The BMD measurements of the hip (total hip and femoral neck) and the anteroposterior lumbar spine (L2-4) were performed by three trained technicians using the same dual energy $x$ ray absorptiometry equipment (Lunar Expert, Madison, Wisconsin). The machine was calibrated daily with a spine phantom supplied by Lunar. Measurements of the left hip and spine were done according to standardised procedures. ${ }^{13}$ In 14 patients no hip measurement was performed as they had had two hip replacements, and in 14 patients the right hip only was measured owing to replacement of severe destruction of the left hip. No spine measurement was performed in one patient.

To ensure uniformity of the results all the scans were reanalysed by one of the experienced technicians after all the data had been collected. The spine phantom precision error calculated as a coefficient of variation $(\mathrm{CV} \%)$ was $0.9 \%$ for the whole measurement period (15 months). The in vivo reproducibility of BMD measurements was assessed from duplicate measurements in 31 healthy female hospital workers (mean age 56.1 years, range 50-66). The CV was $2.2 \%$ at the lumbar spine, $1.5 \%$ at the total hip, and $1.5 \%$ at the femoral neck. The interobserver variation for the three trained technicians performing measurements and analyses was assessed by pairwise comparisons of analyses of 30 randomly selected patients with RA. The precision varied from 0.7 to $1.4 \%$ at the spine L2 -4 , from 0.4 to $0.5 \%$ in the total hip, and from 0.5 to $0.8 \%$ in the femoral neck.

The BMD measurements in the RA population were compared with a pooled European/US reference population aged 2069 , based on different normal data from Europe and US, containing 9505 women with hip and 10281 with spine measurements. ${ }^{16-24}$ The variation of mean BMD values among the geographical sites in this pooled population was about $1.3 \%$ (SD/mean). ${ }^{16}$ The reference database comprised measures of ambulatory subjects generally free from earlier fractures, chronic diseases, and drugs influencing bone metabolism (for example, corticosteroids, anticonvulsant drugs, and thyroxine).$^{16}$

The BMD data for the pooled European/US reference population were provided by Lunar Corporation, Madison, including the data for $\mathrm{T}$ score estimations. For $\mathrm{T}$ score estimations the following mean (SD) BMD results for young adults (age 20-39) were used: femoral neck $0.98(0.12) \mathrm{g} / \mathrm{cm}^{2}$, total hip $1.00(0.12)$ $\mathrm{g} / \mathrm{cm}^{2}$, and spine L2-4 $1.20(0.12) \mathrm{g} / \mathrm{cm}^{2}$.

\section{ETHICS AND LEGAL ASPECTS}

The local ethic committee approved this study. The Data Inspectorate had approved the register of patients with RA in Oslo.

\section{DATA ANALYSES}

Data analysis was performed in the total female patient group $(n=394)$ and, separately, for patients aged over $50(n=271)$. All analyses were performed with SPSS, version 8.0.

Osteoporosis was defined as a $\mathrm{T}$ score $\leqslant-2.5 \mathrm{SD},{ }^{25}$ low bone mass as $\mathrm{T}$ score $\leqslant-1$. After computing the number of patients with osteoporosis and low bone mass, bivariate comparisons of demographic, disease activity, and disease severity measures between patients with and without osteoporosis/low bone mass were performed, using two sided $t$ tests (continuous variables) and $\chi^{2}$ tests (counts).

Independent variables to be used in the multivariate analyses were dichotomised as 
Table 1 Demographic variables and measures of disease activity and severity in the study samples. Mean (SD) for continuous variables, \% for counts

\begin{tabular}{|c|c|c|}
\hline & $\begin{array}{l}\text { All patients } \\
(n=394)\end{array}$ & $\begin{array}{l}50-70 \text { years } \\
(n=271)\end{array}$ \\
\hline \multicolumn{3}{|l|}{ Demographic variables } \\
\hline Age (years) & $54.8(11.6)$ & $61.5(6.2)$ \\
\hline $\mathrm{BMI}^{\star}\left(\mathrm{kg} / \mathrm{m}^{2}\right)$ & $24.0(4.2)$ & $24.5(4.4)$ \\
\hline Menopause (\%) & 66.0 & 91.9 \\
\hline Menopause age (years) & $47.9(5.5)$ & $48.1(5.4)$ \\
\hline Oophorectomy $(\%)$ & 4.3 & 4.8 \\
\hline Current users of oestradiol (\%) & 28.5 & 35.4 \\
\hline Bisphosphonates (\%) & 2.6 & 3.8 \\
\hline \multicolumn{3}{|l|}{ Smoking } \\
\hline Non-smoker $(\%)$ & 33.0 & 30.5 \\
\hline Previous smoker (\%) & 30.5 & 32.4 \\
\hline Current smoker $(\%)$ & 36.5 & 37.0 \\
\hline \multicolumn{3}{|l|}{ Disease variables } \\
\hline Disease duration (years) & $13.0(9.4)$ & $14.3(10.2)$ \\
\hline Rheumatoid factor positive (\%) & 52.0 & 54.3 \\
\hline Investigator's global assessment (VAS ${ }^{\star} 0-100 \mathrm{~mm}$ ) & $28.7(24.1)$ & $32.0(25.3)$ \\
\hline Patient's global assessment $(1-5)$ & $2.63(0.88)$ & $2.72(0.91)$ \\
\hline $\mathrm{MHAQ}^{\star}($ range $1-4)$ & $1.61(0.50)$ & $1.70(0.51)$ \\
\hline Pain (VAS 0-100 mm) & $36.1(21.9)$ & $39.7(22.0)$ \\
\hline Fatigue (VAS $0-100 \mathrm{~mm}$ ) & $44.9(27.8)$ & $46.4(28.0)$ \\
\hline 28 Swollen joint count & $7.84(6.11)$ & $8.48(6.28)$ \\
\hline 28 Tender joint count & $6.84(6.36)$ & $7.53(6.67)$ \\
\hline 18 Deformed joint count & $2.15(3.70)$ & $2.63(4.05)$ \\
\hline $\mathrm{ESR}^{\star}(\mathrm{mm} / 1 \mathrm{st} \mathrm{h})$ & $21.6(16.5)$ & $23.2(17.4)$ \\
\hline $\mathrm{CRP}^{\star}(\mathrm{mg} / \mathrm{l})$ & $16.2(11.9)$ & $16.5(12.3)$ \\
\hline DAS* & $4.49(1.37)$ & $4.70(1.33)$ \\
\hline \multicolumn{3}{|l|}{ Corticosteroids } \\
\hline Never user (\%) & 36.3 & 30.7 \\
\hline Previous user (\%) & 23.2 & 23.4 \\
\hline Current user $(\%)$ & 40.5 & 46.0 \\
\hline Non-vertebral fracture $(\%)$ & 21.2 & 26.5 \\
\hline
\end{tabular}

${ }^{\star} \mathrm{BMI}=$ body mass index; VAS $=$ visual analogue scale; $\mathrm{MHAQ}=$ Modified Health Assessment Questionnaire; ESR = erythrocyte sedimentation rate; $\mathrm{CRP}=\mathrm{C}$ reactive protein; $\mathrm{DAS}=$ disease activity score.

follows: age over and under 60 years, BMI and DAS divided by the two highest and lowest quartiles, presence and absence of deformed joints, MHAQ score $\geqslant 1.5$ (indicating physical disability), corticosteroids into current versus not users, and presence versus absence of previous non-vertebral fracture.

The occurrence of such possible predictors of osteoporosis (age $\geqslant 60$ years, low BMI, high DAS, deformed joints, MHAQ $\geqslant 1.5$, current user of corticosteroids, previous non-vertebral fracture) were compared between patients with and without osteoporosis/low bone mass. These possible predictors were subsequently entered into a logistic regression analysis applying osteoporosis/low bone mass at different sites as dependent variables. The logistic regression analyses were run with the enter procedure.

\section{Results}

PATIENTS

Table 1 shows the demographic and clinical characteristics of the 394 female patients with RA finally included in the study, born 1926 and later, and the 271 patients aged between 50 and 70 .

Of all the women with RA from the register, born 1926 or later $(n=721)$, there were no statistically significant differences in age, disease duration, and rheumatoid factor positivity between those measured and not measured. A group of 109 patients had clinical examinations, without bone mass measurement. The clinical and disease characteristics, including disease activity and severity measures, in these patients did not differ from those whose BMD was measured. Thus, the final sample of 394 patients with RA seems to be representative of the overall RA population in the county.

BMD MEASURES

The BMD values (mean (SD) in $\mathrm{g} / \mathrm{cm}^{2}$ ) for the whole patient group were $1.10(0.21)$ at the spine L2-4, $0.87(0.16)$ at the total hip, and $0.85(0.16)$ at the femoral neck. Corresponding values in the 50-70 age group were 1.05 (0.20), 0.83 (0.16), and $0.80(0.15)$.

The percentages $(95 \%$ confidence interval (CI)) having osteoporosis ( $\mathrm{T}$ score $\leqslant-2.5 \mathrm{SD}$ ) were in the total patient group 16.8 (13.1 to 20.5) at L2-4, 14.7 (11.1 to 18.3) at the total hip, and 14.7 (11.1 to 18.3 ) at the femoral neck. Among those aged 50-70 the percentages were as expected higher (23.3 (18.3 to 28.3), 21.1 (16.2 to 26.0), and 20.7 (15.9 to 25.5)). The percentages (95\%CI) with low bone mass ( $\mathrm{T}$ score $\leqslant-1 \mathrm{SD}$ ) were $45.8(40.9$ to 50.7 ), 54.5 (49.5 to 59.5 ), and 55.5 (50.5 to $60.5)$ in the spine L2-4, total hip, and femoral neck, respectively.

\section{COMPARISON OF PATIENTS WITH AND WITHOUT} OSTEOPOROSIS/LOW BONE MASS

Table 2 gives bivariate comparisons of demographic and disease activity and severity variables between patients with and without osteoporosis. Osteoporosis was statistically associated with increasing age, longer disease duration, lower BMI, increasing disease activity, and use of corticostertoids at all sites of measurement. The computed DAS also

Table 2 Comparison of demographic and disease activity/severity variables between patients with and without osteoporosis. Means for continuous variables, \% for counts

\begin{tabular}{|c|c|c|c|c|c|c|c|c|c|}
\hline & \multicolumn{3}{|c|}{ Spine L2-4 } & \multicolumn{3}{|l|}{ Total hip } & \multicolumn{3}{|c|}{ Femoral neck } \\
\hline & $\begin{array}{l}T \leqslant-2.5 \\
(n=66)\end{array}$ & $\begin{array}{l}T>-2.5 \\
(n=327)\end{array}$ & $p$ Value & $\begin{array}{l}T \leqslant-2.5 \\
(n=56)\end{array}$ & $\begin{array}{l}T>-2.5 \\
(n=324)\end{array}$ & $p$ Value & $\begin{array}{l}T \leqslant-2.5 \\
(n=56)\end{array}$ & $\begin{array}{l}T>-2.5 \\
(n=324)\end{array}$ & $p$ Value \\
\hline Age (years) & 62.8 & 53.2 & $<0.001$ & 63.9 & 53.0 & $<0.001$ & 63.7 & 53.1 & $<0.001$ \\
\hline Disease duration (years) & 15.9 & 12.3 & 0.007 & 16.9 & 11.8 & $<0.001$ & 16.0 & 11.9 & 0.005 \\
\hline Body mass index & 22.9 & 24.2 & 0.006 & 22.5 & 24.2 & 0.002 & 22.7 & 24.2 & 0.005 \\
\hline Number of swollen joints & 9.92 & 7.44 & 0.01 & 11.19 & 7.16 & $<0.001$ & 11.46 & 7.11 & $<0.001$ \\
\hline Number of deformed joints & 4.16 & 1.77 & $<0.001$ & 4.89 & 1.49 & $<0.001$ & 4.63 & 1.54 & $<0.001$ \\
\hline $\mathrm{CRP}^{\star}(\mathrm{mg} / \mathrm{l})$ & 18.0 & 15.8 & 0.17 & 20.9 & 14.7 & 0.001 & 19.9 & 14.9 & 0.005 \\
\hline $\mathrm{ESR}^{\star}(\mathrm{mm} / 1 \mathrm{st} \mathrm{h})$ & 24.7 & 21.1 & 0.16 & 26.6 & 20.1 & 0.008 & 26.5 & 20.1 & 0.01 \\
\hline $\mathrm{MHAQ}^{\star}$ & 1.74 & 1.59 & 0.06 & 1.81 & 1.56 & 0.002 & 1.74 & 1.57 & 0.02 \\
\hline DAS $^{\star}$ & 4.88 & 4.42 & 0.02 & 5.08 & 4.37 & 0.001 & 5.05 & 4.37 & 0.001 \\
\hline Current use of corticosteroids (\%) & 66.1 & 35.3 & $<0.001$ & 64.8 & 35.2 & $<0.001$ & 66.7 & 34.9 & $<0.001$ \\
\hline Ever use of corticosteroids (\%) & 80.6 & 60.3 & 0.002 & 85.2 & 58.7 & $<0.001$ & 83.3 & 59.0 & 0.001 \\
\hline Rheumatoid factor positive (\%) & 58.3 & 50.6 & 0.32 & 68.6 & 48.9 & 0.01 & 67.3 & 49.0 & 0.02 \\
\hline Non-vertebral fracture (\%) & 33.9 & 18.6 & 0.007 & 37.0 & 17.3 & 0.001 & 44.4 & 16.0 & $<0.001$ \\
\hline
\end{tabular}

${ }^{\star} \mathrm{CRP}=\mathrm{C}$ reactive protein; $\mathrm{ESR}=$ erythrocyte sedimentation rate; $\mathrm{MHAQ}=$ Modified Health Assessment Questionnaire; DAS $=$ disease activity score. 
Table 3 Possible risk factors of osteoporosis at the spine L2-4. Occurrence and logistic regression analysis

\begin{tabular}{|c|c|c|c|c|c|c|c|}
\hline & \multicolumn{3}{|c|}{ Occurrence (\%) } & \multicolumn{4}{|c|}{ Logistic regression analysis } \\
\hline & $\begin{array}{l}T \leqslant-2.5 \\
(n=66)\end{array}$ & $\begin{array}{l}T>-2.5 \\
(n=327)\end{array}$ & $p$ Value & $\beta$ & $S E$ & $O R$ & $C I$ \\
\hline Age $\geqslant 60$ & 77.3 & 33.9 & $<0.001$ & 1.87 & 0.36 & 6.46 & 3.18 to 13.13 \\
\hline $\mathrm{BMI}^{\star} 2$ lowest quartiles & 62.1 & 47.7 & 0.04 & 1.26 & 0.35 & 3.52 & 1.77 to 6.99 \\
\hline Deformed joints & 54.8 & 35.6 & 0.006 & 0.50 & 0.33 & 1.65 & 0.87 to 3.14 \\
\hline $\mathrm{MHAQ}^{\star} \geqslant 1.5$ & 59.0 & 50.2 & 0.21 & -0.26 & 0.36 & 0.77 & 0.38 to 1.56 \\
\hline $\mathrm{DAS}^{\star} 2$ highest quartiles & 65.5 & 47.9 & 0.02 & 0.27 & 0.36 & 1.31 & 0.64 to 2.67 \\
\hline Current use of corticosteroids & 66.1 & 35.3 & $<0.001$ & 1.07 & 0.34 & 2.91 & 1.50 to 5.65 \\
\hline Non-vertebral fracture & 33.9 & 18.6 & 0.007 & 0.50 & 0.36 & 1.65 & 0.82 to 3.32 \\
\hline Constant & & & & -4.32 & 0.51 & & \\
\hline Sensitivity/specificity (\%) & & & & & & $52 / 87$ & \\
\hline
\end{tabular}

${ }^{\star} \mathrm{BMI}=$ body mass index MHAQ = Modified Health Assessment Questionnaire; DAS = disease activity score.

Table 4 Possible risk factors of osteoporosis at the total hip. Occurrence and logistic regression analysis

\begin{tabular}{|c|c|c|c|c|c|c|c|}
\hline & \multicolumn{3}{|c|}{ Occurrence } & \multicolumn{4}{|c|}{ Logistic regression analysis } \\
\hline & $\begin{array}{l}T \leqslant-2.5 \\
(n=56)\end{array}$ & $\begin{array}{l}T>-2.5 \\
(n=324)\end{array}$ & $p$ Value & $\beta$ & $S E$ & $O R$ & $C I$ \\
\hline Age $\geqslant 60$ & 82.1 & 33.3 & $<0.001$ & 2.58 & 0.44 & 13.23 & 5.58 to 31.33 \\
\hline $\mathrm{BMI} \star 2$ lowest quartiles & 66.1 & 47.5 & 0.01 & 1.82 & 0.41 & 6.16 & 2.76 to 13.75 \\
\hline Deformed joints & 59.3 & 32.7 & $<0.001$ & 0.75 & 0.37 & 2.12 & 1.03 to 4.36 \\
\hline $\mathrm{MHAQ}^{\star} \geqslant 1.5$ & 66.0 & 47.8 & 0.02 & 0.42 & 0.41 & 1.52 & 0.68 to 3.39 \\
\hline $\mathrm{DAS}^{\star} 2$ highest quartiles & 68.6 & 47.6 & 0.006 & 0.01 & 0.42 & 1.01 & 0.45 to 2.29 \\
\hline Current use of corticosteroids & 64.8 & 35.2 & $<0.001$ & 1.00 & 0.39 & 2.71 & 1.27 to 5.78 \\
\hline Non-vertebral fracture & 37.0 & 17.3 & 0.001 & 0.67 & 0.40 & 1.96 & 0.90 to 4.27 \\
\hline Constant & & & & -5.63 & 0.65 & & \\
\hline Sensitivity/specificity (\%) & & & & & & $56 / 89$ & \\
\hline
\end{tabular}

${ }^{\star} \mathrm{BMI}=$ body mass index $\mathrm{MHAQ}=$ Modified Health Assessment Questionnaire; DAS = disease activity score.

discriminated between patients with and without osteoporosis. Osteoporosis was more consistently related to disease activity and severity measures at the hip location than at the spine L2-4 site of measurement (table 2).

Similar patterns of differences were seen for demographic and disease variables between patients with and without low bone mass (data not shown).

RISK FACTORS FOR OSTEOPOROSIS

Tables 3-5 present bivariate comparisons and logistic regression analyses of the associations between osteoporosis and categorised risk factors (age, BMI, joint deformity, disability, DAS, current use of corticosteroids, and previous non-vertebral fracture). Table 6 presents the multivarate relations between low bone mass and the categorised risk factors.

Patients with osteoporosis differed for all tested variables (table 4) from those without osteoporosis of the total hip, whereas group differences were not found for physical disability (MHAQ $\geqslant 1.5)$ between patients with and without osteoporosis at the spine L2-4 (table 3 ) and femoral neck (table 5). The same trends

Table 5 Possible risk factors of osteoporosis at the femoral neck. Occurrence and logistic regression analysis

\begin{tabular}{|c|c|c|c|c|c|c|c|}
\hline & \multicolumn{3}{|c|}{ Occurrence (\%) } & \multicolumn{4}{|c|}{ Logistic regression analysis } \\
\hline & $\begin{array}{l}T \leqslant-2.5 \\
(n=56)\end{array}$ & $\begin{array}{l}T>-2.5 \\
(n=324)\end{array}$ & $p$ Value & $\beta$ & $S E$ & $O R$ & $C I$ \\
\hline Age $\geqslant 60$ & 78.6 & 34.0 & $<0.001$ & 2.17 & 0.42 & 8.80 & 3.88 to 19.98 \\
\hline $\mathrm{BMI}^{\star} 2$ lowest quartiles & 66.1 & 47.5 & 0.01 & 1.76 & 0.41 & 5.82 & 2.60 to 13.00 \\
\hline Deformed joints & 57.4 & 33.0 & 0.001 & 0.67 & 0.37 & 1.96 & 0.95 to 4.02 \\
\hline $\mathrm{MHAQ}^{\star} \geqslant 1.5$ & 60.4 & 48.7 & 0.14 & -0.10 & 0.40 & 0.91 & 0.41 to 2.00 \\
\hline DAS $\star 2$ highest quartiles & 70.6 & 47.2 & 0.002 & 0.37 & 0.42 & 1.44 & 0.64 to 3.27 \\
\hline Current use of corticosteroids & 66.7 & 34.9 & 0.001 & 1.12 & 0.38 & 3.05 & 1.44 to 6.48 \\
\hline Non-vertebral fracture & 44.4 & 16.0 & $<0.001$ & 1.29 & 0.39 & 3.63 & 1.71 to 7.73 \\
\hline Constant & & & & -5.46 & 0.63 & & \\
\hline Sensitivity/specificity (\%) & & & & & & $68 / 90$ & \\
\hline
\end{tabular}

${ }^{\star} \mathrm{BMI}=$ body mass index; $\mathrm{MHAQ}=$ Modified Health Assessment Questionnaire; DAS $=$ disease activity score.

Table 6 Possible risk factors of low bone mass (T score $\leqslant-1)$ at the spine L2-4, total hip, and femoral neck

\begin{tabular}{|c|c|c|c|c|c|c|c|c|c|}
\hline & \multicolumn{3}{|c|}{ Spine L2-4 } & \multicolumn{3}{|c|}{ Total hip } & \multicolumn{3}{|c|}{ Femoral neck } \\
\hline & $\bar{\beta}$ & $O R$ & $C I$ & $\beta$ & OR & $C I$ & $\beta$ & $O R$ & $C I$ \\
\hline Age $\geqslant 60$ & 1.29 & 3.62 & 2.21 to 5.92 & 1.13 & 3.10 & 1.81 to 5.29 & 1.42 & 4.13 & 2.43 to 7.01 \\
\hline $\mathrm{BMI}^{\star} 2$ lowest quartiles & 0.89 & 2.43 & 1.49 to 3.97 & 1.43 & 4.17 & 2.45 to 7.11 & 0.86 & 2.37 & 1.44 to 3.92 \\
\hline Deformed joints & -0.08 & 0.93 & 0.57 to 1.50 & 0.48 & 1.62 & 0.97 to 2.70 & 0.48 & 1.61 & 0.98 to 2.66 \\
\hline $\mathrm{MHAQ}^{\star} \geqslant 1.5$ & 0.48 & 1.62 & 0.97 to 2.71 & 0.84 & 2.31 & 1.35 to 3.97 & 0.62 & 1.86 & 1.10 to 3.14 \\
\hline $\mathrm{DAS}^{\star} 2$ highest quartiles & 0.19 & 1.20 & 0.72 to 2.00 & -0.04 & 0.96 & 0.56 to 1.65 & 0.12 & 1.13 & 0.67 to 1.91 \\
\hline Current use of corticosteroids & 0.89 & 2.44 & 1.51 to 3.93 & 0.75 & 2.11 & 1.27 to 3.53 & 0.55 & 1.74 & 1.05 to 2.86 \\
\hline Non-vertebral fracture & 0.47 & 1.59 & 0.89 to 2.85 & 1.17 & 3.23 & 1.63 to 6.37 & 0.69 & 2.00 & 1.05 to 3.83 \\
\hline Constant & -1.97 & & & -2.06 & & & -1.63 & & \\
\hline Sensitivity/specificity (\%) & & $69 / 70$ & & & $74 / 69$ & & & $73 / 65$ & \\
\hline
\end{tabular}

${ }^{\star} \mathrm{BMI}=$ body mass index; $\mathrm{MHAQ}=$ Modified Health Assessment Questionnaire; DAS = disease activity score. 
were found for patients aged 50-70, but owing to the lower sample size not all differences reached statistical significance (data not shown).

Age over 60, low BMI, and current use of corticosteroids were the most consistent risk factors in multivariate analyses for osteoporosis and low bone mass (tables 3-6). The presence of deformed joints was associated with osteoporosis at the total hip, and a history of previous non-vertebral fracture with osteoporosis at the femoral neck (tables 4 and 5). MHAQ $\geqslant 1.5$ and non-vertebral fracture were independently associated with low bone mass at the hip.

The classification tables showed that models generally reached a sensitivity between 50 and $60 \%$ and specificity between 80 and $90 \%$ for osteoporosis (tables 3-5) and a sensitivity and specificity of about $70 \%$ for low bone mass (table 6).

In addition to the model examining the main effects, an expanded model which included all first order interactions was fitted. The overall test for all the interactions turned out to be non-significant. Consequently, the main effects model had an adequate fit.

\section{Discussion}

This study confirms that patients with RA with osteoporosis and low bone mass generally have a more active and severe disease than patients without osteoporosis. Thus markers of disease activity and severity as well as treatment with corticosteroids indicate an increased risk of osteoporosis. However, this study also highlights that these associations with clinical markers are weak, as increasing age and low BMI were the strongest and most consistent predictors of osteoporosis at all sites, both in the total patient group and in the analyses of patients aged 50-70. Age and BMI are also consistent predictors in postmenopausal osteoporosis, ${ }^{26}$ suggesting that these demographic variables may be more important at a group level than the disease factors.

However, clinical markers are also important, even if the logistic regression models used had rather low sensitivity in detecting patients with osteoporosis. The most important clinical factor was the current use of corticosteroids, and then the presence of deformed joints, indicating structural joint damage. In this cross sectional approach the DAS and the MHAQ score did not turn out to be independent predictors of osteoporosis, and the MHAQ score only reached borderline statistical significance at one measurement site. Analyses were also performed with low bone mass as the dependent variable because the threshold of the $\mathrm{T}$ score $\leqslant-1 \mathrm{SD}$ may be as important when advocating treatment, especially in patients using corticosteroids. ${ }^{8}$

The results can be used to compute algorithms of some help in clinical practice. The predicted probabilities for a combination of clinical variables can be calculated by adding the parameter estimates from any combinations. For example, the results in table 4 indicate that the odds of having total hip osteoporosis for women in the oldest age group and lowest BMI group with inactive and not severe disease is:

logit (constant, age $\geqslant 60$, BMI two lowest quartiles, not deformed joints, MHAQ $\leqslant 1.5$, DAS two lowest quartiles, no use of corticosteroids, and no previous nonvertebral fracture $)=\operatorname{logit}(-5.63+2.58$ $+1.82+0+0+0+0+0)$,

while the odds for having osteoporosis for women with the same age and BMI characteristics, but with severe and active disease and previous nonvertebral fracture is:

logit (constant, age $\geqslant 60$, BMI two lowest quartiles, deformed joints, $M H A Q \geqslant 1.5$, DAS two highest quartiles, current use of corticosteroids, and previous nonvertebral fracture $)=\operatorname{logit}(-5.63+2.58$ $+1.82+0.75+0.42+0.01+1.00+$ 0.67 ).

The log odds ratio (OR) for women over 60 and with low BMI with active and severe disease and with previous non-vertebral fracture compared with those without active disease and with no previous non-vertebral fracture is:

$(\operatorname{logit}(-5.63+2.58+1.82+0.75+0.42+$ $0.01+1.00+0.67))-(\operatorname{logit}(-5.63+$ $2.58+1.82+0+0+0+0+0))=1.62$ $-(-1.23)=2.85$.

Thus the OR for having total hip osteoporosis for those with compared with those without active and severe disease and a previous history of non-vertebral fracture is: $\mathrm{e}^{2.85}=17.29$, where $\mathrm{e}$ is the base of the natural logarithms, approximately 2.718 .

It can be argued that other disease activity measures should have been included in the model. A lot of exploratory analyses were done before we decided to use the present model, which incorporates various dimensions of measures that are recommended for longitudinal observational studies ${ }^{27}$ and also may be used in the routine clinical care of patients with RA.

For corticosteroids we chose to use current instead of ever use of corticosteroids as the independent variable as corticosteroid induced bone loss may be reversed when corticosteroid treatment is stopped. ${ }^{28}$ In the exploratory analyses we found that acute phase reactants, number of swollen joints, and rheumatoid factor were not independent predictors. From the group comparisons it was also shown that only marginal differences were seen for these variables between the patients with and without osteoporosis (table 2). This result partially contradicts the results of a previous study showing that the mean ESR measured during the six months before the BMD measurement was negatively associated with hip BMD. ${ }^{29} \mathrm{We}$ had expected a stronger effect of the MHAQ level on osteoporosis, as this previous Dutch study also found an association between physical disability and BMD. ${ }^{29}$ The level of MHAQ is, however, closely related to age, and age came out as the strongest overall predictor. 
Previous studies on osteoporosis in RA have mainly focused on selected groups of patients recruited from referral centres. ${ }^{23} 3031$ In our study we had a different approach, examining patients from a county based RA register. This register has been examined for its completeness and includes about $85 \%$ of the total underlying patient population, ${ }^{10}$ and prevalence data have shown a twofold increase in osteoporosis in patients with RA. ${ }^{13}$ Furthermore, the patients examined did not differ significantly from the patients on the register who were eligible for this study. Thus our results are relevant for all patients with RA as a group, but different results might have been found if similar analyses had been performed in selected patients with active and severe disease, or in a selected group of patients who were not receiving hormone replacement therapy. It should be noted that more than one quarter of the patients in this study were current users of oestradiol. However, the results were similar when we repeated the analyses in a subsample excluding users of oestradiol (data not shown).

The effect of inflammatory markers on osteoporosis might also have been different if longitudinal data had been analysed. ${ }^{62}$ For radiographic progression it is well known that the level of acute phase reactants correlates with structural damage. ${ }^{32}$ This correlation has been shown to be even stronger if, for example, a series of CRP measurements are related to radiographic damage. ${ }^{33}$

The important clinical outcome of low bone mass is symptomatic fracture. The incidence of hip and vertebral fractures is increased in patients with RA, but the relation between bone mass and subsequent fractures remains to be established. ${ }^{34}$ It is not certain whether data from patients with postmenopausal osteoporosis, showing a double risk of fracture for each $\mathrm{SD}$ reduction in $\mathrm{BMD},{ }^{35}{ }^{36}$ is also applicable to patients with RA. In our study a history of non-vertebral fracture was used as a possible predictor, showing an independent relation with osteoporosis and low bone mass in the hip, but not in the lumbar spine.

Our aim was to develop a clinical tool which would be helpful in the identification of patients with RA who were likely to develop osteoporosis. We found that osteoporosis and low bone mass in RA are more consistenly associated with age, BMI, and current use of corticosteroids than disease variables. Osteoporosis could be predicted with an average sensitivity of only $50-60 \%$ and a specificity of $80-90 \%$ when the predictors were combined into logistic regression models. This indicates that consideration of risk factors may be helpful in clinical practice, but that many patients with osteoporosis will be missed if only those with known risk factors, including high disease activity and severity, are considered.

We thank Petter Mowinchel for statistical advice, our technicians, Ingerid Müller, Sidsel Arnkværn, and Espen Haavardsholm, for expert assistance with the BMD measurements, and research secretary Kirsten Mossin for keeping the Oslo Rheumatoid Arthritis Register updated.

This study was funded by grants from The Research Council of Norway, Lions Club International MD 104 Norway, the Norwegian Women Public Health Association, Trygve Gyth- feldt and Wife's Legacy, Grethe Harbitz's Legacy, and Marie and Else Mustad's Legacy.

1 Deodhar AA, Woolf AD. Bone mass measurement and bone metabolism in rheumatoid arthritis: a review. Br J Rheumatol 1996;35:309-22.

2 Hall GM, Spector TD, Griffin AJ, Jawad AS, Hall ML, Doyle DV. The effect of rheumatoid arthritis and steroid therapy on bone density in postmenopausal women.
Arthritis Rheum 1993;36:1510-16.

3 Martin JC, Munro R, Campbell MK, Reid DM. Effects of disease and corticosteroids on appendicular bone mass in postmenopausal women with rheumatoid arthritis: comparison with axial measurements. Br J Rheumatol 1997;36: 43-9.

4 Dequeker J, Westhovens R. Low dose corticosteroid associated osteoporosis in rheumatoid arthritis and its prophylaxis and treatment: bones of contention. J Rheumatol 1995;22:1013-19.

5 Eggelmeijer F, Camps JA, Valkema R, Papapoulos SE, Pauwels EK, Dijkmans BA, et al. Bone mineral density in ambulant, non-steroid treated female patients with rheumatoid arthritis. Clin Exp Rheumatol 1993;11:381-5.

6 Gough AK, Lilley J, Eyre S, Holder RL, Emery P. Generalised bone loss in patients with early rheumatoid arthritis. Lancet 1994;344:23-7.

7 Eastell R. Management of corticosteroid-induced osteoporosis. UK Consensus Group Meeting on Osteoporosis. J Intern Med 1995;237:439-47.

8 American College of Rheumatology Task Force. Recommendations for the prevention and treatment of glucocorticoid-induced osteoporosis. American College of Rheumatology Task Force on Osteoporosis Guidelines. Arthritis Rheum 1996;39:1791-801.

9 Lems WF, Dijkmans BAC. Should we look for osteoporosis in patients with rheumatoid arthritis? Ann Rheum Dis 1998;57:325-7.

10 Kvien TK, Glennås A, Knudsrød OG, Smedstad LM, Mowinckel P, Førre $\varnothing$. The prevalence and severity of rheumatoid arthritis in Oslo: results from a county register and 18 .

11 Arnett FC, Edworthy SM, Bloch DA, McShane DJ, Fries JF, Cooper NS, et al. The American Rheumatism AssociaJF, Cooper NS, et al. The American Rheumatism Association 1987 revised criteria for the classification of
toid arthritis. Arthritis Rheum 1988;31:315-24.

12 Uhlig T, Kvien TK, Glennås A, Smedstad LM, Førre $\varnothing$ The incidence and severity of rheumatoid arthritis, results from a county register in Oslo, Norway. J Rheumatol 1998; 25:1078-84.

13 Haugeberg G, Uhlig T, Falch JA, Halse JI, Kvien TK. Bone mineral density and frequency of osteoporosis in female patients with rheumatoid arthritis. Results from 394 patients in the Oslo County Rheumatoid Arthritis Register. Arthritis Rheum 2000;43:522-30.

14 van Gestel AM, Haagsma CJ, Van Riel PL. Validation of rheumatoid arthritis improvement criteria that include simplified joint counts. Arthritis Rheum 1998;41:1845-50.

15 Pincus T, Summey JA, Soraci SA Jr, Wallston KA, Hummon NP. Assessment of patient satisfaction in activities of daily living using a modified Stanford Health Assessment Questiving using a modified Stanford Health Assess

16 Lunar Corporation. Operator's Manual, Expert-XL, software version 1.8. Madison, WI: Lunar Corporation, 1998. 17 Karlsson MK, Gardsell P, Johnell O, Nilsson BE, Akesson $\mathrm{K}$, Obrant KJ. Bone mineral normative data in Malmo, Sweden. Comparison with reference data and hip fracture incidence in other ethnic groups. Acta Orthop Scand 1993; 64:168-72.

18 Kroger H, Heikkinen J, Laitinen K, Kotaniemi A. Dual-energy X-ray absorptiometry in normal women: a cross-sectional study of 717 Finnish volunteers. Osteoporos Int 1992;2:135-40

19 Laitinen K, Valimaki M, Keto P. Bone mineral density measured by dual-energy X-ray absorptiometry in healthy Finnish women. Calcif Tissue Int 1991;48:224-31.

20 Wetzel R, Pfandl S, Bodenburg R, Puhl W. Knochendichte Referenzwerte von deutschen Frauen - Untersuchung der LWS mit dem Lunar DPX-Densitometer. Osteologie 1996;5:71-81.

21 Burger H, van Daele PL, Algra D, van den Ouweland FA, Grobbee DE, Hofman A, et al. The association between age and bone mineral density in men and women aged 55 age and bone mineral density in men and women aged 55 years and over:

22 Krall EA, Dawson-Hughes B, Hirst K, Gallagher JC, Sherman SS, Dalsky G. Bone mineral density and biochemical markers of bone turnover in healthy elderly men and women. J Gerontol A Biol Sci Med Sci 1997;52: 61-7.

23 Mazess RB, Barden HS, Eberle RW, Denton MD. Age changes of spine density in posterior-anterior and lateral projections in normal women. Calcif Tissue Int 1995;56: 201-5.

24 Truscott JG, Simpson D, Fordham JN. Compilation of national bone densitometry reference data. In: Ring EFS, Elvins DM, Ghalla AK, eds. Current research in osteoporosis and bone mineral measurement IV.London: The British Institute of Radiology, 1996:77-8.

25 Kanis JA, Melton LJ, Christiansen C, Johnston CC, Khaltaev N. The diagnosis of osteoporosis. J Bone Miner

26 Mazess RB, Barden H. Bone density of the spine and femur in adult white females. Calcif Tissue Int 1999;65:91-9. 
27 Wolfe F, Lassere $M$, van der Heijde D, Stucki G, Suarez-Almazor M, Pincus T, et al. Preliminary core set of domains and reporting requirements for longitudina observational studies in rheumatology. J Rheumato 1999;26:484-9.

28 Laan RF, Van Riel PL, van de Putte LB, van Erning LJ, van't Hof MA, Lemmens JA. Low-dose prednisone induces rapid reversible axial bone loss in patients with rheumatoid arthritis. A randomized, controlled study. Ann Intern Med 1993;119:963-8.

29 Laan RF, Buijs WC, Verbeek AL, Draad MP, Corstens FH, van de Putte LB, et al. Bone mineral density in patients with recent onset rheumatoid arthritis: influence of disease activity and functional capacity. Ann Rheum Dis 1993;52: 21-6.

30 Peel NF, Moore DJ, Barrington NA, Bax DE, Eastell R. Risk of vertebral fracture and relationship to bone mineral density in steroid treated rheumatoid arthritis. Ann Rheum Dis 1995;54:801-6.

31 Sambrook PN, Eisman JA, Yeates MG, Pocock NA, Eberl S, Champion GD. Osteoporosis in rheumatoid arthritis: Champion GD. Osteoporosis in rheumatoid arthritis: 1986;45:950-3.
32 van Leeuwen MA, van Rijswiik MH, Van der Heijde DM, Te Meerman GJ, Van Riel PL, Houtman PM, et al. The acute-phase response in relation to radiographic progression in early rheumatoid arthritis: a prospective study during the first three years
1993;32(suppl 3):9-13.

33 van Leeuwen MA, van Rijswijk MH, Sluiter WJ, Van Riel PL, Kuper IH, van de Putte LB, et al. Individual relationship between progression of radiological damage and the acute phase response in early rheumatoid arthritis. Towards development of a decision support system. J Rheumatol 1997;24:20-7.

34 Peel NF, Moore DJ, Barrington NA, Bax DE, Eastell R. Risk of vertebral fracture and relationship to bone mineral density in steroid treated rheumatoid arthritis. Ann Rheum Dis 1995;54:801-6.

35 Ross PD, Davis JW, Epstein RS, Wasnich RD. Pre-existing fractures and bone mass predict vertebral fracture incifractures and bone mass predict vertebral fracture
dence in women. Ann Intern Med 1991;114:919-23.

36 Cummings SR, Black DM, Nevitt MC, Browner W, Cauley $\mathrm{J}$, Ensrud $\mathrm{K}$, et al. Bone density at various sites for prediction of hip fractures. The Study of Osteoporotic Fractures Research Group. Lancet 1993;341:72-5. 